\title{
Happy 85th Anniversary!
}

DOI: $10.1134 / \mathrm{S} 1063739709060018$

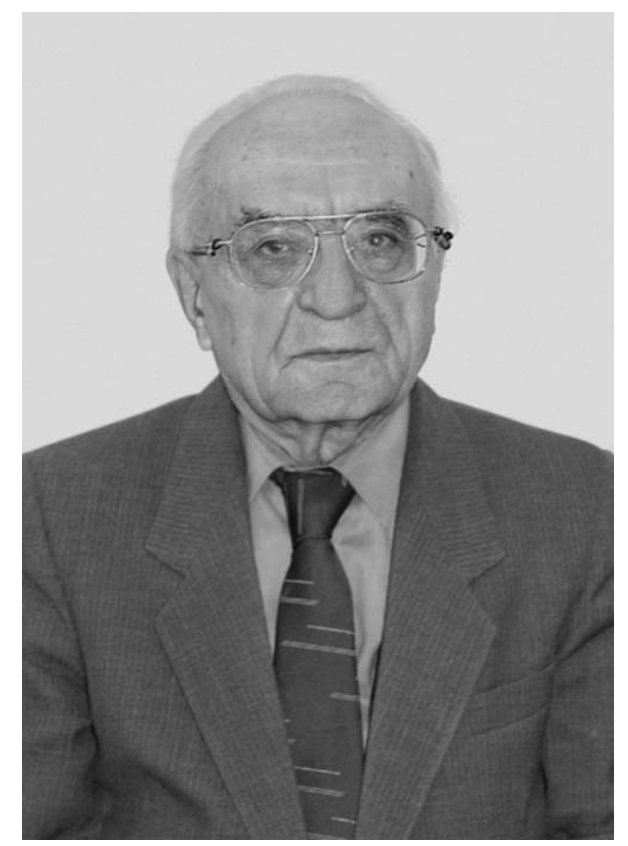

On August 13, Professor Tatevos Mamikonovich Agakhanyan, one of the leading specialists in electronics and microelectronics, celebrated his 85th anniversary.

Agakhanyan was born on August 13, 1924 in Ashtarak, Armenia. He has been attached to electronics and microelectronics throughout his life. He is a Merited Worker of Science of the Russian Federation. In 1952 Agakhanyan graduated from the Moscow Physical Engineering Institute (MIFI) with a degree in engineering physics. He defended his candidate's dissertation in 1958 and doctoral dissertation in 1969. He became Professor of the Department of Electronics in 1969. He has worked in the department of Electronics, MIFI, since 1952, and has occupied the positions of head of laboratories and senior engineer. In 1956 he started his pedagogic career: at first, as an assistant, then senior teacher, assistant professor, and professor. For more than 26 years (from 1965 through 1991) he headed the department of Electronics, the largest of the institute's graduate Departments.

He has developed and realized more than ten educational courses in electronics and prepared more than
30 candidates of science, many of whom became renowned doctors of science. He is a prominent specialist in the basic knowledge on the theory and practice of transistors and transistor schemes and in the issues of radiation effects on transistor structures and microschemes. He is the author of more than 200 scientific works, 6 author's certificates and 14 monographs, two of which were translated into foreign languages. $\mathrm{He}$ is a participant of the Great Patriotic War, holder of two Orders of the Patriotic War of the first degree, Order of Friendship of Peoples, and 33 medals. He is an Honorable Professor of MIFI.

Prof. Agakhanyan has been a member of the editorial board of the journal Mikroelektronika for many years, taking an active part in its work. Through his qualified and friendly recommendations and advice, he helped many young scientists and specialists in publishing their articles in the journal.

The editorial board of the journal Mikroelektronika cordially congratulates Prof. Agakhanyan on his 85th birthday, and wish good health and continued success in his important and useful work. 